\title{
INTERTIDAL FINGER BARS AT EL PUNTAL SPIT, BAY OF SANTANDER, SPAIN
}

\author{
Roland Garnier', Raúl Medina', Erica Pellón' ${ }^{1}$, Albert Falqués ${ }^{2}$ and Imen Turki ${ }^{1,3}$
}

\begin{abstract}
We indentify the presence of an intertidal finger bar system in the swell-protected beaches of El Puntal Spit (Bay of Santander, Spain). The Horus video monitoring system allows us to perform a 2 year survey (June 2008- June 2010). We found that the bar system persists during the survey period with a wavelength of about $25 \mathrm{~m}$ and an oblique orientation with respect to the shore. Moreover, the analysis of the position of a particular bar (Bar 10) shows a movement characterized by a net migration to the west and a faster oscillation to the east or the west. Preliminary climate data analysis and morphological model results show that tide seems to be a forcing in the motion of the bars but also wind and waves generated by the wind probably affects the bar dynamics.
\end{abstract}

Keywords: intertidal finger bar; Horus video monitoring system; estuarine morphodynamics; surf-zone morphodynamics; transverse/oblique bars

\section{INTRODUCTION}

The Bay of Santander is located in the northern coast of Spain (Gulf of Biscay). It is one of the largest inlets in the Cantabrian Coast. It is bounded northward by the city of Santander and by El Puntal spit (Figure 1). The bay is connected to the open sea through a section N-S bounded by the Magdalena Peninsula (north) and the western end of El Puntal spit (south).

El Puntal spit is a $2.5 \mathrm{~km}-$ long sandy spit with a W-E orientation, exposed northward to the Atlantic Ocean and protected southward from the incoming swell. Although the morphology of beaches in the northern face of El Puntal is very well documented (see for instance Losada et al., 1992 and Medellín et al., 2008), a specific study on the southern beaches is missing. One particularity of the southern beaches is the presence of elongated (finger) sand bars that appear in the intertidal zone (Figure 1).

The objective of this study is twofold: (1) characterizing the shape and the dynamics of these tidal finger bars with the help of the Horus video monitoring system and (2) analyzing the different forcings that could act on the bar dynamics by using climate data and a numerical tool (process based model) based on self-organization.

This study is organized as follows. Firstly a description of the bar is presented. Secondly the Horus video monitoring system is used to describe the bar evolution. Thirdly, the possible forcing candidates are presented. Fourthly preliminary model results are shown. Finally conclusions and further work are given.
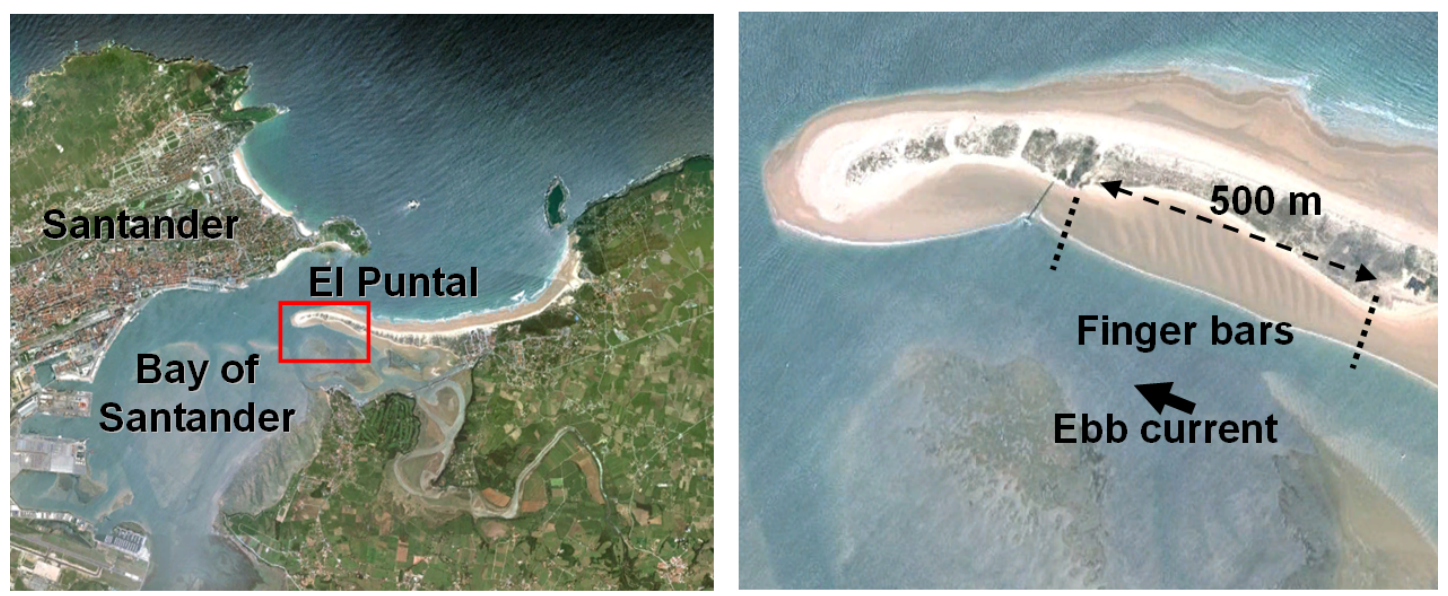

Figure 1. Left: localization of the study site: the Bay of Santander. Right: Zoom of the intertidal finger bars at El Puntal spit at low tide. Image source: Google Earth imagery $\odot$ DigitalGlobe and GeoEye.

\footnotetext{
${ }^{1}$ Environmental Hydraulics Institute "IH Cantabria", Universidad de Cantabria, c /Isabel Torres n 15 , Santander, 39011, Spain.

${ }^{2}$ Applied Physics Dept, Universitat Politécnica de Catalunya, C/ Jordi Girona 1-3, Barcelona, 08034, Spain.

${ }^{3}$ Now at: M2C, Universite de Rouen, Campus de Mont-Saint Aignant, 76000 CEDEX, France.
} 


\section{BAR DESCRIPTION}

The intertidal finger bars at El Puntal spit are persistent rhythmic features that are fully emerged at low tide (Figure 2). The spacing between two bars is about $25 \mathrm{~m}$. During the survey period, the number of the bars has been between 15 and 20 and no reset event has been observed. They have an oblique orientation with respect to the shoreline, being up-current oriented with respect to the ebb flow (this means that they open an acute angle against the ebb current, see Figure 1). The bar angle is about 25 deg ( 0 deg would correspond to transverse bars, and 90 deg to shore parallel bars). The bar height (vertical distance between the bar crest and the nearest trough) is less than $50 \mathrm{~cm}$. A slight asymmetry in the alongshore profiles of the bar system has been detected, with a gentle down-current slope and a steeper up-current slope with respect to the ebb flow.
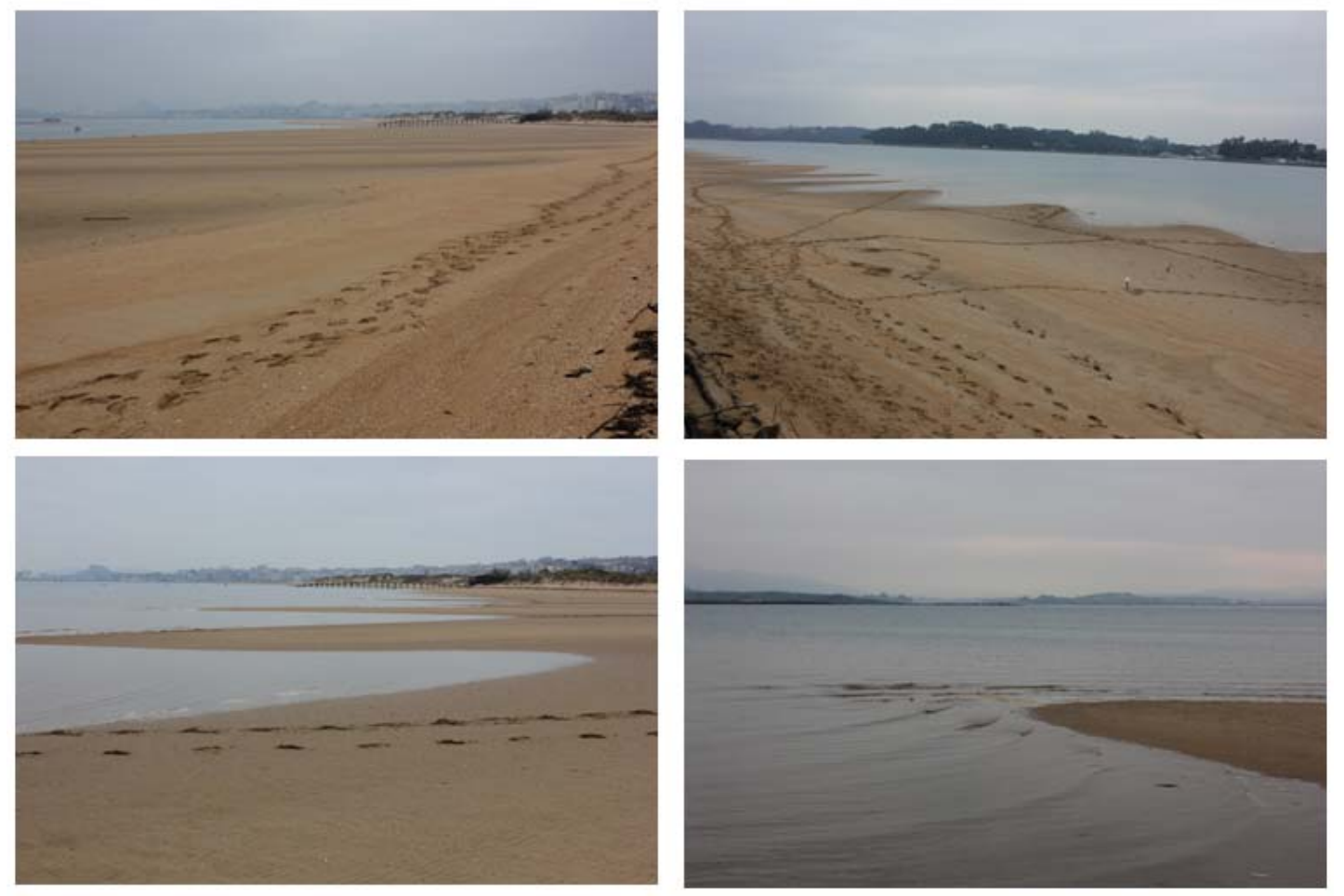

Figure 2. Photos of the intertidal finger bars for different tidal levels. At low tide the bars are fully emerged. At mid tide, the coastline exhibits a cuspate shape. At high tide, the bars are fully submerged (not shown).

\section{VIDEO IMAGERY}

\section{Horus Video System}

An Argus video monitoring system (Holman et al., 1993) was installed in front of El Puntal in 2003. This Argus system was originally designed for the management of the navigation channel of the Santander Bay entrance (Medina et al., 2007). The system has also been used for research purposes and particularly for studying beach morphologies at the northern part of El Puntal (the beaches exposed to the Atlantic ocean) by Medellín et al, 2008 and 2009. They have observed the presence of coastline sand waves with a wave length of $125-150 \mathrm{~m}$.

From 2008, the video monitoring has been performed by the recently developed Horus system (www.horusvideo.com). In the present study, Horus is tested on the beaches located in the southern part of El Puntal, where the transverse bars have been observed (Figure 3). The Horus video system consists of four video cameras pointing to El Puntal spit, located at $1.5 \mathrm{~km}$ westward of the bar system. In the study area the video system provides a pixel resolution of $0.5 \mathrm{~m}$ in the cross-shore direction and $5 \mathrm{~m}$ in the alongshore direction. Here, only camera 2 is used (Figure 3). We used daily images from June 2008 to June 2010. 

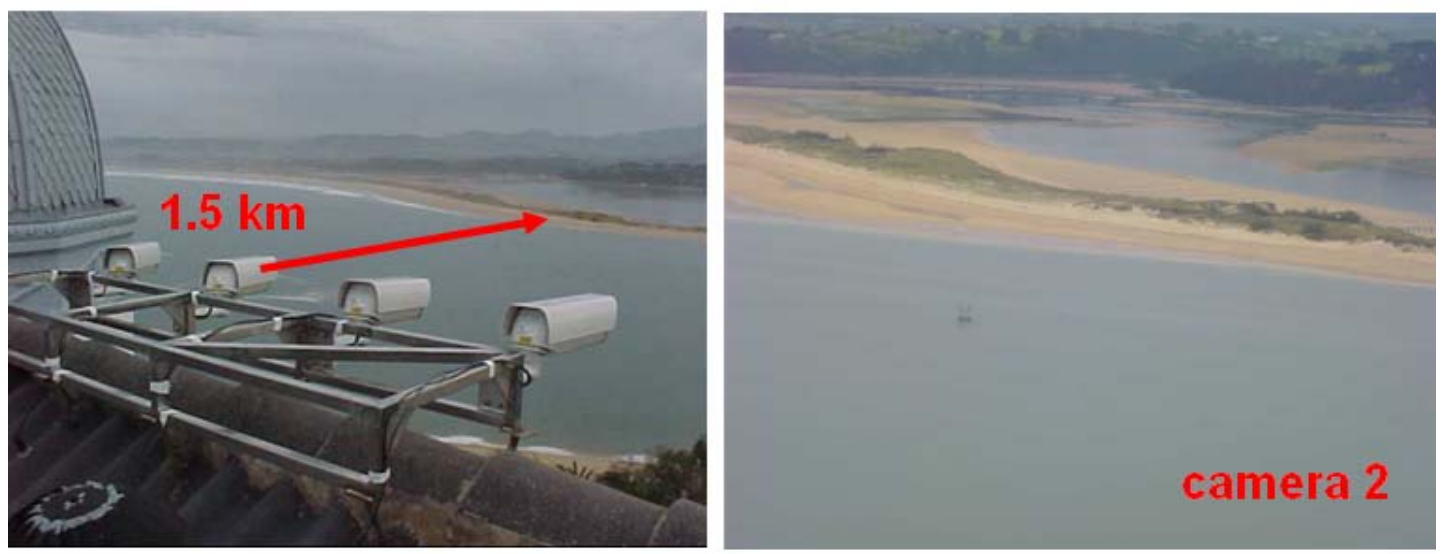

Figure 3. The Horus video system (www.horusvideo.com). Left: localization of the four cameras (on top of Hotel Real, Santander, Spain). Right: image of the bar system taken by camera 2.

\section{Bar Characterization}

Time exposure images have been used. They are images with intensity averaging over $10 \mathrm{~min}$ and a sampling rate of $0.5 \mathrm{~s}$. Every day during the survey period (June 2008 - June 2010), the best quality image of the bars at low tide has been selected.

The bar digitization has been performed by representing each bar by 2 segments ( 3 points, see Figure 4). During the survey period, between 13 and 15 bars have been digitized, depending on the meteorological conditions and on the bar configurations. Here, we present the results of the position of Bar 10. The position is obtained from the intersection between the digitized Bar 10 with an arbitrary chosen axis $y$ that is parallel to the low tide level (Figure 4). The $y$ axis also indicates the alongshore direction.

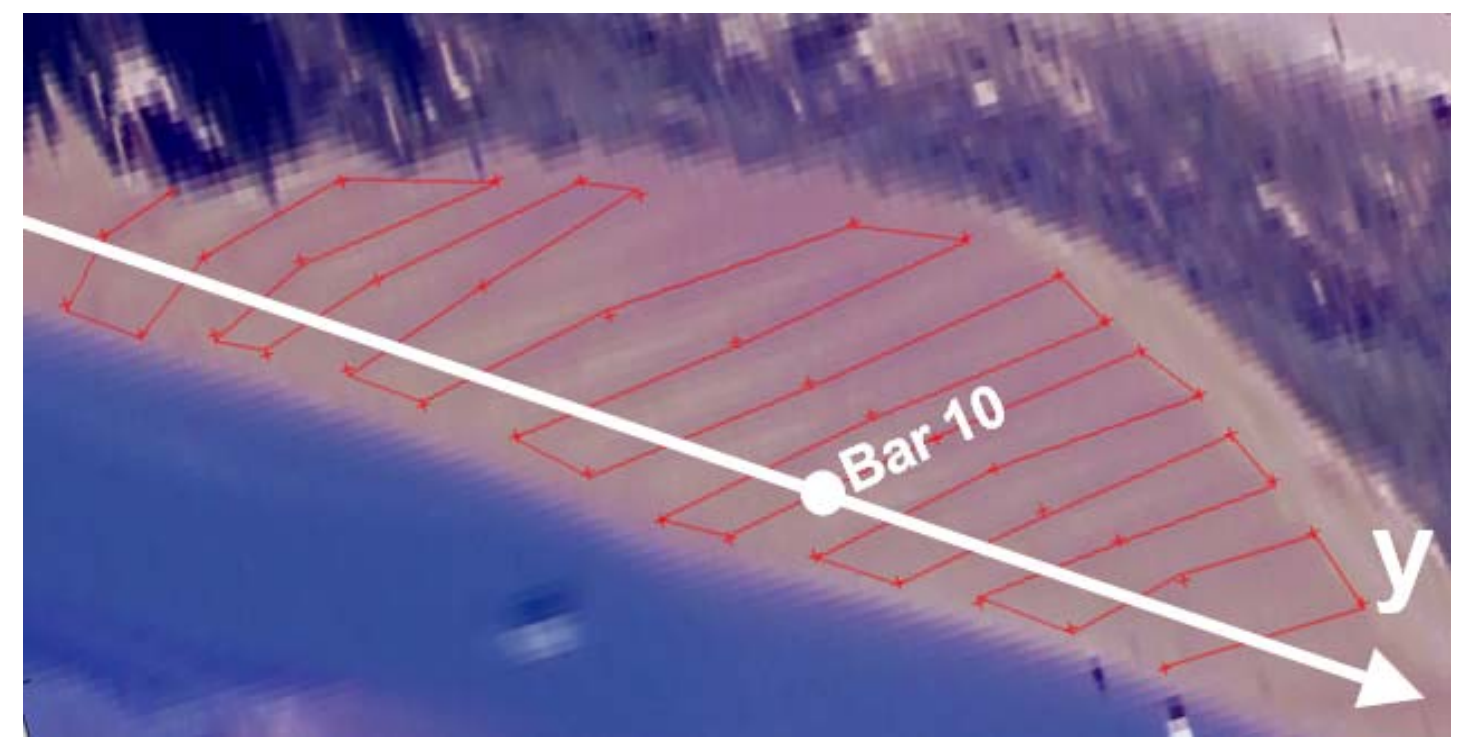

Figure 4. Bar digitization method. Each bar is represented by 2 segments (3 points). The position of Bar 10 is obtained from the intersection of the digitized Bar 10 and the alongshore axis $y$. 


\section{Bar Evolution}

The position of Bar 10 is shown in Figure 5. The initial position of the bar $(340 \mathrm{~m})$ is arbitrary. Here we focus on the bar translation from the initial position. We notice a net positive translation during the 2 year survey, showing that the bar migrates to the east (to the inside of the bay) at a net speed of $6 \mathrm{~cm}$ /day for 2 years (Figure 5, Top). Moreover, we observe 'fast' oscillations that can be captured by subtracting the bar position with its 22 day moving average (Figure 5, Bottom). This fast movement is characterized by velocities higher than $+/-10 \mathrm{~m}$ /day a $10 \%$ of time (negative velocities mean migration to the west). Interestingly, the Fourier analysis of the position signal gives a maximum at 15 days (not shown) that corresponds to the spring tides period. Finally, the slow evolution of the bars obtained with the 22 day moving average shows velocities of up to $+/-0.7 \mathrm{~m} /$ day.
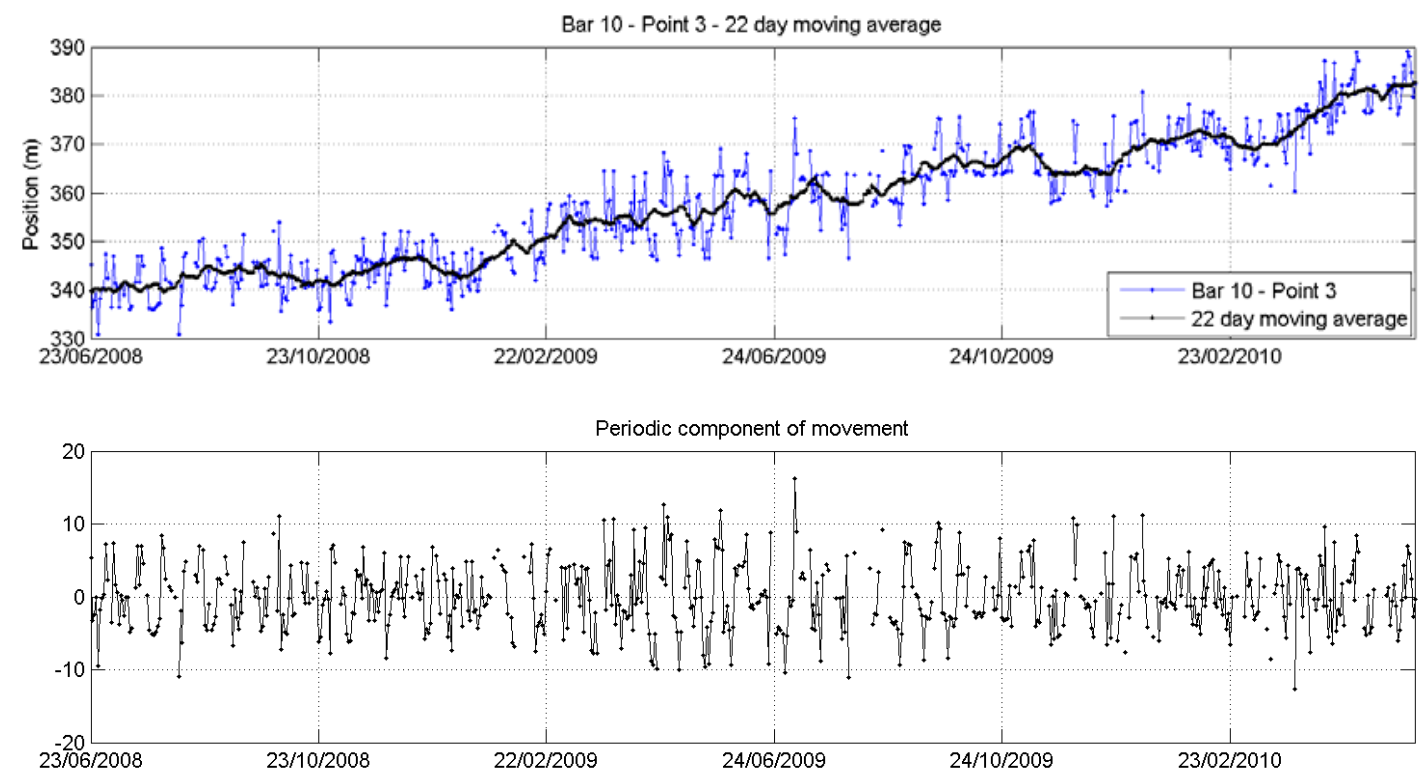

Figure 5. Analysis of the position of Bar 10. Top: position of Bar 10 (blue line) and its 22 day moving average (black line). Bottom: fast movement of the bar obtained by subtracting the bar position and the 22 day moving average.

\section{FORCING CANDIDATES}

As commented in the previous section, from Fourier analysis, the spectrum of the bar position has a maximum that corresponds to the frequency of the spring tides (see Figure 6a, where the maximum daily level of the exterior tides is plotted). This suggests the importance of the tide in the bar dynamics and that the tide could explain this fast bar motion.

In order to quantify the tidal current in the study area, preliminary simulations (not shown) have been performed with the numerical regional hydrodynamic model H2D (Medina and Castanedo, 1996). By using a rough grid of $50 \mathrm{~m} * 50 \mathrm{~m}$ in the computational domain, an ebb-dominated flow in the neighborhood of the bars is obtained.

Interestingly, during the two years of survey, a net migration of the bar to the inside of the bay $(6 \mathrm{~cm} /$ day) has been observed, that is an up-ebb current migration. A bar migrating against the dominant current is intriguing, as it is not a common result in nearshore sand bar studies (Ribas et al., 2003; Garnier et al., 2006). This allows us to wonder about (1) the validity of the hydrodynamic model results (i.e., is the flow really ebb-dominated in the location of the bars?) and (2) the existence of other forcing that pushes the bars to the east. To clarify this dilemma further work is needed. Work in process includes: climate data analysis in order to indentify the possible other forcings, application of hydrodynamic numerical models particularly with better resolution, field measurements, and application of morphological numerical models. 
The presence of other forcing is presumed as the slow bar motion that we identified in the previous section (speed of $+/-0.7 \mathrm{~m} /$ day) does not seem to be related to any tidal level fluctuations. Here, we present two forcing candidates that can act in the bar dynamics. (1) The wind that blows more frequently and more intensively from the west (Figure 6b). Results of the SeaWind model (Fita et al., 2009) show a wind magnitude of up to $80 \mathrm{~km} / \mathrm{h}$ during the 2 year survey. (2) Although the location area is protected from the Atlantic swell, the 4-km maximum fetch of the Santander bay is enough to generate waves. Results of the SWAN model (Booij, 1981) show that the wind can generate waves of up to $50 \mathrm{~cm}$ (Figure 6c).

\section{a)}

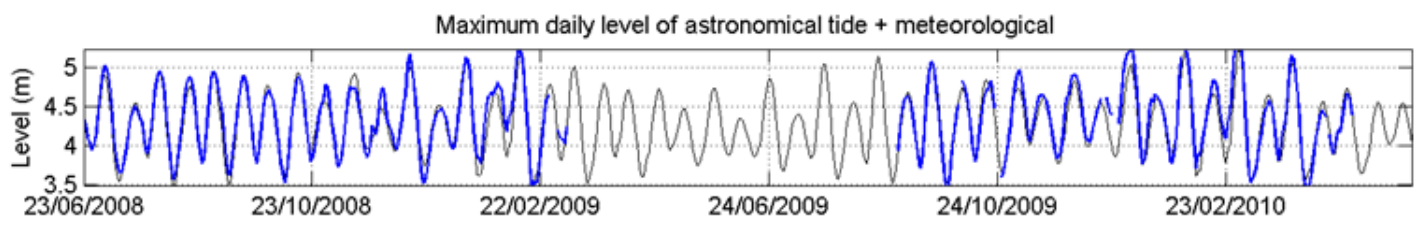

b)

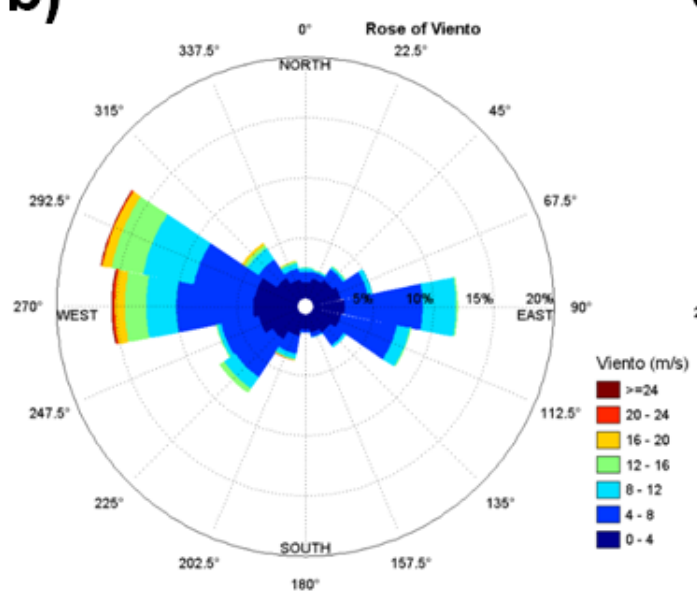

c)

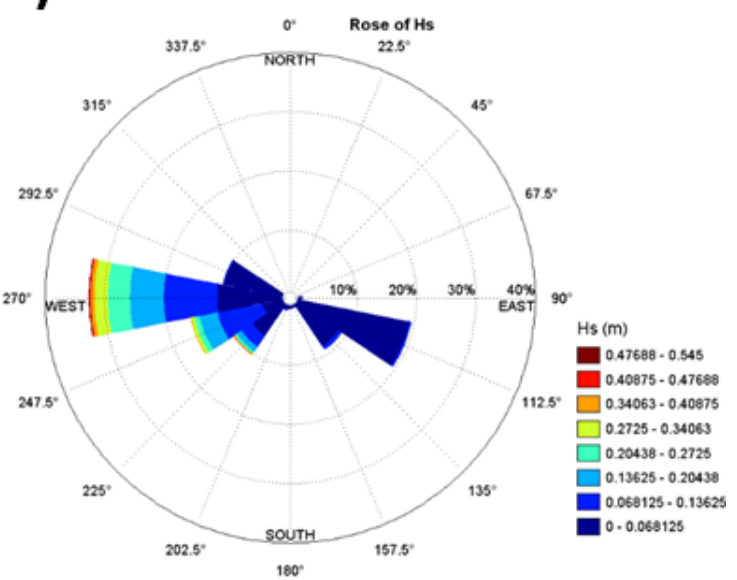

Figure 6. Forcing candidates. (a) Maximum daily levels of the astronomical tide (gray) and of the total tide (astronomical + meteorological, blue), obtained from Santander tide-gauge data. (b) Wind rose obtained for the 2 year survey in the study area with the SeaWind Model (Fita et al., 2009). (c) Wave rose obtained with SWAN model for the 2 years (Booij, 1981).

\section{PRELIMINARY NUMERICAL SIMULATIONS}

\section{MORFO55 model}

MORFO55 is a nonlinear numerical model based on a wave and depth averaged shallow water equation solver with wave driver, sediment transport and bed updating. The governing equations have already been presented by Caballeria et al., 2002; Garnier et al., 2006; 2008 and 2010. It is able to reproduce the formation and the long-term evolution of rhythmic sand bars as free instabilities of alongshore uniform beaches excited by a small perturbation added on the initial topography.

Originally MORFO55 has been designed for the study of the surf zone and the forcing was made by waves only. MORFO55 is here extended in order to disconnect the wave forcing and to include forcing by wind and by tide that generates sea level gradients. In order to simplify the study and to better understand the mechanisms on the formation and on the behavior of the finger bars, only submerged zone is considered. In other words, we consider that the bars are fully immerged, moreover the tidal level is assumed as a constant.

Concerning the sediment transport formula, a crude approximation has been made. We assume that the sediment flux is given by:

$$
\vec{q}=\alpha\left(\vec{v}-\mu_{o} \nabla h\right)
$$


where $\alpha$ is the sediment stirring factor (in $\mathrm{m} 3 / \mathrm{m} 2$ ), $\vec{v}$ is the depth averaged current vector, $\gamma$ is the bedslope parameter, $u_{0}$ is the wave orbital velocity at the bottom and $h$ is the bottom perturbation with respect to the initial bathymetry. For simplicity the sediment stirring factor is considered as a constant $(\alpha=0.001 \mathrm{~m})$. This crude approximation has already been assumed in morphological modelling studies (see Ribas et al., 2003, Garnier et al., 2006). This is the first step before including more sophisticated formulations and this allows us to have a first understanding in the bar dynamics.

\section{Model Set-Up}

Three kinds of experiments have been performed by considering those three forcings by separately: tide, wind and waves. The initial bathymetry is assumed alongshore uniform with a constant slope during the first $120 \mathrm{~m}$ (See Figure 7a). The maximum depth is $2 \mathrm{~m}$. In order to evaluate the effect of the different forcings, the model has been run in its hydrodynamic mode (the sediment transport has been disconnected). Figure 7a shows the resulting cross-shore profiles of the alongshore current. We see that the order of magnitude of the velocity is the same for the three forcings (about 0.1 $\mathrm{m} / \mathrm{s})$.

Morphological experiments have been performed from the bathymetry shown in Figure $7 \mathrm{~b}$, where a small random perturbation has been added to the alongshore uniform beach. The size of the computational domain is $300 \mathrm{~m}$ in the alongshore direction and $150 \mathrm{~m}$ in the cross-shore direction. The grid size is $2 \mathrm{~m} * 2 \mathrm{~m}$.

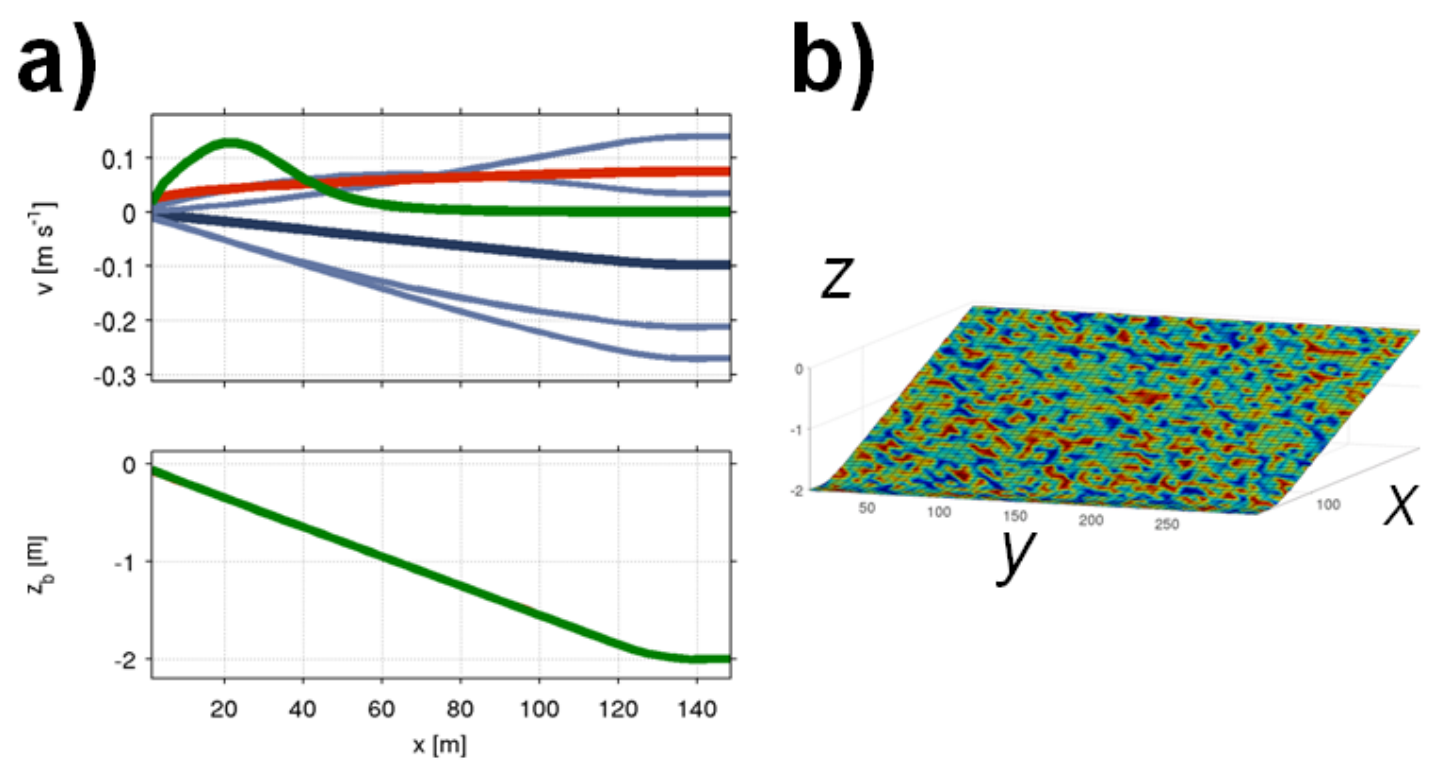

Figure 7. (a) Hydrodyamic experiments (basic states). The bottom plot indicates the initial bathymetric profile $(x=0$ is the shoreline), maximum depth is $2 \mathrm{~m}$. The top plot shows the resulting longshore current for different forcings. Blue curves: forcing due to tidal level gradients (off-shore tidal range of $5 \mathrm{~m}$, spring tide), the light blue curves have been obtained by considering variable tidal level gradients, the dark blue curve is the mean current (negative means ebb-dominated). Red curve: forcing due to wind (wind from South West, velocity of $60 \mathrm{~km} / \mathrm{h}$ ). Green curve: forcing due to wind-waves of $20 \mathrm{~cm}$ height and $2 \mathrm{~s}$ period (assuming that these waves are generated by the same SW wind). (b) Initial bathymetry for the morphological experiments.

\section{Preliminary results}

An overview of the model simulations is given in Figure 8. It shows snapshots of the morphological evolution at two different times for the three forcing (a) the tide, (b) the wind and (c) the waves. In the three cases we observe the formation of rhythmic bars. The spacing between two bars has the same order as the spacing observed $(25 \mathrm{~m})$. In the simulations, it oscillates between $25 \mathrm{~m}$ and $150 \mathrm{~m}$ depending on the stage of the evolution and on the forcing. The growth rates of the bars obtained for the three experiments are close: from 0.2 day $^{-1}$ to 0.6 day $^{-1}$. This suggests that these three forcings can act on the formation of the finger bars. 
As a result, the orientation of the bars is found up-current or down-current (with respect to the mean current) with an angle between $25 \mathrm{deg}$ and $50 \mathrm{deg}$ (90 deg being the direction parallel to the coastline). The bars migrate with velocities between 2 and $10 \mathrm{~m} /$ day that are much faster than the mean migration speeds observed ( $6 \mathrm{~cm} /$ day). However, here, the simulations represent extreme conditions so that the velocities can be compared to the maximum observed daily velocity that is about $10 \mathrm{~m} /$ day.

From these preliminary results, we can argue that tide, wind, and waves generated by wind are possible forcings for the origin of the transverse finger bars and that they can induce their migrations. However, further work is needed to simulate the combining effects of tide, wind and waves, and to include more realistic input data from accurate climate data analysis (see previous section).

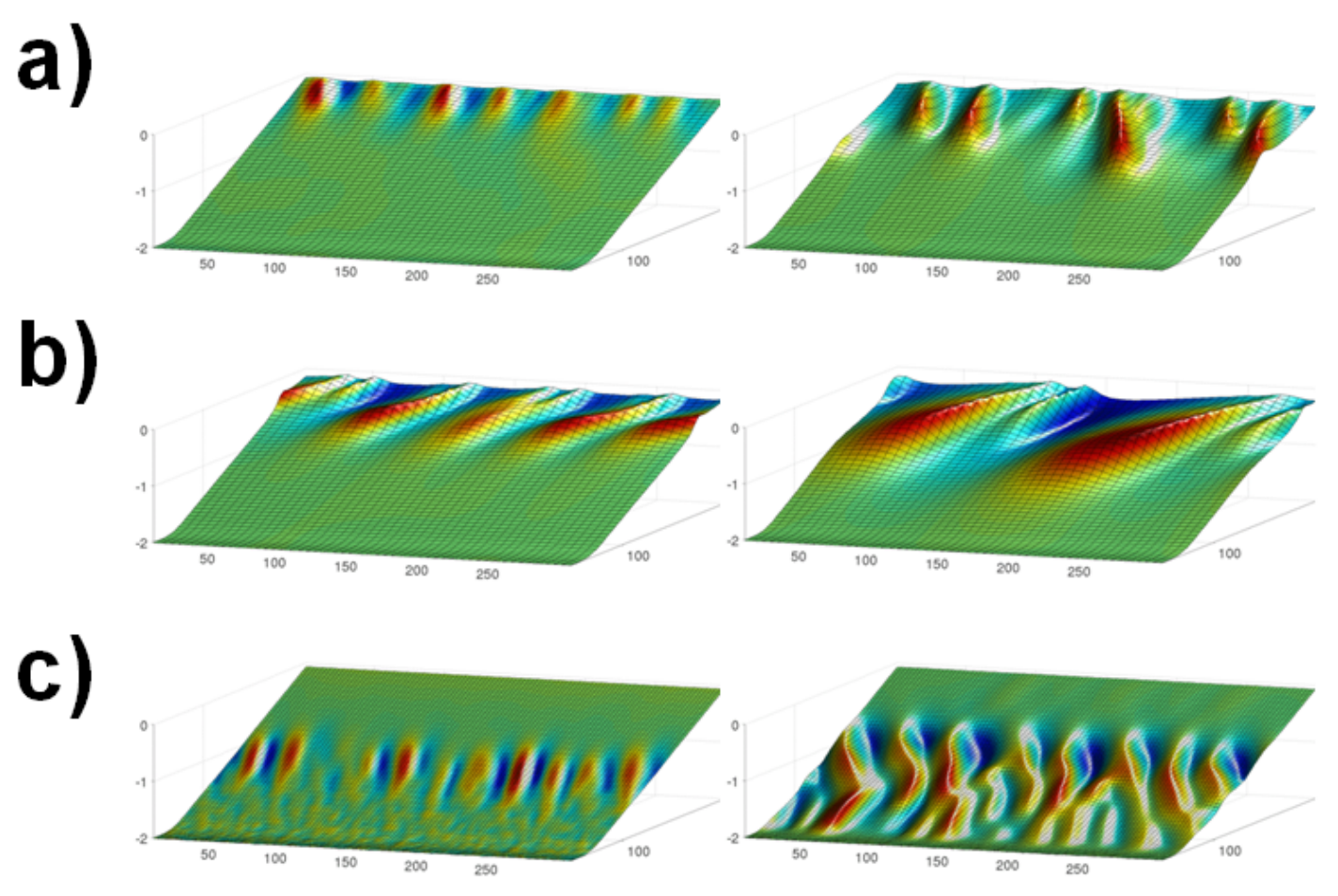

Figure 8. Preliminary model simulations. Formation and evolution of rhythmic bars for different forcings. Left: initial state of the evolution (about 10 days). Right: advanced state of the evolution (about 20 days). (a) Tidal forcing, mean current coming from the right (east). (b) Wind forcing, mean current coming from the left (SW wind). (c) Wave forcing, mean current coming from the left (wave generated by SW wind).

\section{CONCLUSIONS}

We performed the survey of the intertidal finger bars of the Bay of Santander during 2 years (June 2008 - June 2010) by using the Horus video monitoring system. We found that the bar system persists during the 2 year survey and the analysis of the position of a particular bar (Bar 10) shows a movement characterized by (1) a net migration to the west (net speed: $6 \mathrm{~cm} /$ day) (2) a slow translation to the east or the west (maximum mean speed: $+/-0.7 \mathrm{~m} /$ day) and (3) a fast periodic translation with a speed of up to $10 \mathrm{~m} /$ day.

The period of the fast movement of the bar is 15 days and corresponds to the period of the spring tides. This suggests the effect of the tide in the bar dynamics. However, other forcings probably act on the bar dynamics as the slow motion observed $(+/-0.7 \mathrm{~m} /$ day) is not related to tidal variations. We indentified two possible forcings that are the wind (blowing predominantly from the west) and the waves generated by the wind (maximum fetch is $4 \mathrm{~km}$ in the SW direction). Further work is needed in order to correlate the possible forcings with the bar movement, by performing climate data analysis and hydrodynamic numerical modelling. 
Preliminary morphological model results show that tide, wind and waves can generate the formation of a transverse bar system and can cause the bar migration. Further work is in process in order to include more realistic climate data, to combine different forcings and to improve the sediment transport parameterization.

\section{ACKNOWLEDGMENTS}

The work of R. Garnier was supported by the Spanish government through the "Juan de la Cierva" program. The authors thank Puertos del Estado (Spanish Government) for providing tide-gauge data.

\section{REFERENCES}

Booij, N. (1981). "Gravity waves on water with non-uniform depth and currents," Report n 81-1, Delft University of Technology, 131.

Caballeria, M., G. Coco, A. Falqués, and D. A. Huntley. 2002. Self-organization mechanisms for the formation of nearshore crescentic and transverse sand bars, J. Fluid Mech., 465, 379-410.

Fita, L., Fernandez, J., Gutiérrez, J.M., and Cofiño, A.S. (2009). SeaWind project: Analysing the sensitivity on horizontal and vertical resolution on WRF simulations. II JMCMO, Valencia.

Garnier, R., Calvete, D., Falqués, A., and Caballeria, M. 2006. Generation and nonlinear evolution of shore-oblique/transverse sand bars. J. Fluid Mech., 567: 327-360.

Garnier R., Calvete D., Falqués A., Dodd N. 2008. Modelling the formation and the long-term behaviour of rip channel systems from the deformation of a longshore bar. J. Geophys. Res., 113, C07053, doi:10.1029/2007JC004632.

Garnier R., Dodd N., Falqués A., Calvete D. 2010. Mechanisms controlling crescentic bar amplitude. J. Geophys. Res., 115,F02007,doi:10.1029/2009JF001407.

Holman, R.A., Sallenger Jr., A.H., Lippmann, T.C.D., Haines, J.W.1993. The application of video image processing to the study of nearshore processes. Oceanography 6 (3), 78-85.

Losada, M.A., Medina, R., Vidal, C. and Losada, I.J. 1992. Temporal and spatial cross-shore distributions of sediment at "El Puntal" spit, Santander, Spain. In: Coastal Engineering 1992, 2251-2264.

Medellín, G., Medina R., Falqués A. and González M. 2008. Coastline sand waves on a low-energy beach at "El Puntal”' spit, Spain. Mar. Geol., 250: 143-156

Medellín, G., Falqués A., Medina R. and González M. 2009. Coastline sand waves on a low-energy beach at El Puntal spit, Spain: Linear stability analysis. J. Geophys. Res., 114, C03022, doi:10.1029/2007JC004426.

Medina, R. and Castanedo, S. 1996. Model H2D - Manual de referencia, Grupo de Ingenería Oceanográfica y Costas, Universidad de Cantabria.

Medina, R., Marino-Tapia, I., Osorio, A.1, Davidson, M. and Martin F.L. 2007. Management of dynamic navigational channels using video techniques. Coastal Engineering, 54, 6-7: 523-537.

Ribas, F., Falqués, A., and Montoto, A. 2003. Nearshore oblique sand bars. J. Geophys.Res., 108 (C4):3119 doi:10.1029/2001JC000985. 